\title{
FUNCTIONAL OR PROCESS APPROACH IN MANAGING THE ORGANIZATION. DECISION DILEMMAS OF MODERN MULTI-ENTITY ORGANIZATIONS
}

\author{
Dariusz SOBOTKIEWICZ \\ University of Zielona Góra, Faculty of Economics and Management; d.sobotkiewicz@wez.uz.zgora.pl, \\ ORCID: 0000-0002-8570-5303
}

Purpose: This elaboration aims at answering the question: Does a domestic subsidiary of a German company apply functional or process approach in management? The first part of the article characterizes the functional and process approach. The second part includes results of the studies on approaches applied in the managing of a subsidiary of a national German company of automotive industry.

Design/methodology/approach: The article is based on the analysis of secondary sources (scientific literature and corporate documents of studied subsidiaries) as well as on the analysis of primary sources (the results of an interview with the director of the company).

Findings: Deciding on a change of approach in the management of a multi-entity organization should be well considered and preceded by a comprehensive analysis of the solutions guaranteeing optimal execution of the tasks resulting in customer satisfaction. While the functional approach exhausts, in a sense, the possibility of its further modification to achieve tangible benefits for the organization, the process approach, despite many problems it can generate, its scale of complexity in implementation, gives greater benefits in terms of capacity to react to external imbalances. The traditional arrangement of functions based on the functional layout will continue to be of interest for the management of the parent unit and subsidiaries.

Research limitations/implications: The elaboration of the approach to management does not fully address the issues and concerns that are presented here. However, they point to many areas that need to be taken into account in further theoretical and empirical studies.

Practical implications: The traditional arrangement of functions based on the functional layout will continue to be of interest for the management of the parent unit and subsidiaries. The business practice provides many examples in this regard, including unsuccessful reorganizations in the "purely" process direction. One might even say that multi-entity organizations applying the parameters of the process organization in full are rather scarce.

Social implications: Not applicable.

Originality/value: It has been shown on the basis of the studies that despite the separation of processes and directing the staff towards the final product the traditional (functional) approach regarding management dominates in the company.

Keywords: Parent company, subsidiary, functional approach, process approach.

Category of the paper: Case study, viewpoint. 


\section{Introduction}

The role of contemporary managers is searching for such organizational solutions that will contribute to improvement of functioning of the whole organization as well as its individual parts. The deployment of more effective solutions than those that already exist is somewhat a result of occurring changes in business environment, stronger actions taken by competition, shortening life cycle of products, growing expectations of clients and developments in information technology. The above mentioned are important in context of discussing the directions of changes and are not the only factors giving managers incentives to introduce new solutions in organizations. There are many articles and elaborations on possible applicable contemporary organizational solutions but business practice does not make a full use of them and still depends on already existing and verified to a lesser or greater extent business solutions. Process approach (or orientation) in management is one to be mentioned. This is not a new solution but many enterprises choose to base their existence on traditional (functional) management. The shift from function to process orientation promotes an increase of organizational efficiency and is an answer to existing corporate problems and challenges. Redesigning the organization from function to process approach demolishes existing corporate order and is quite of a challenge for enterprises aiming at reorientation of corporate management approach. The choice between functional and process approach seems harder in case of multientity organizations. It can be assumed that there are more aspects taken into consideration and it is far more complicated than in "classic" enterprises because it refers to both the structure of the organization and its internal economic entities.

The aim is to answer the question: Does a Polish subsidiary of the German company apply functional or process approach in management? The article is based on the analysis of secondary sources (scientific literature and corporate documents of studied subsidiaries) as well as on the analysis of primary sources (the results of an interview with the director of the company).

\section{From a functional approach to process management in the organization}

A functional approach in organization management relies on functional structures, hierarchical dependencies, grouping tasks around functions, their locations in distinct organizational units (units, departments, organizational divisions), in the so-called "Functional silos" with specific empowerment and responsibilities. There are organizational goals around such formalised functions that are in fact independent of the objectives assigned to other functions of the organization. The management of individual functions, and thus autonomous 
parts of the organization, promotes duplication of many managerial tasks and is, in a sense, conflictive. The scope and frequency of conflicts between functional areas increases alongside with the size of the organization. The result gained from a particular function comes forward in the functional approach which in turn is the result gained by an individual organizational unit. It is a determiner of the success or failure of employees centred around the function. All organizational units are responsible for the final product or service but only to the extent of the tasks assigned. In turn, employees focus on the implementation of specific tasks within the scope of a function. Any changes, including optimizations, take place within the framework of "functional silos", their structures, human resources, tasks, empowerments or responsibilities.

A process approach, also known as process orientation, is a kind of management philosophy for any organization (enterprise, institution) that puts processes and clients (external and internal) in the centre of management and employees interest (Nowosielski, 2008, pp. 58-70). In a process approach organizations perceive their own activities through processes and teams performing processes rather than through functions and their implementers assigned to specific units or departments. The management system as well as the layout of positions and organizational units are centred around processes. The processes are characterised by a tendency to cross the boundaries determined by the functions being performed according to Sz. Cyfert and K. Krzakiewicz (Cyfert, Krzakiewicz, 2006, p. 199). In addition, they interweave each other by creating a network of different bilateral contacts between employees, organizational units and the external environment. Most commonly the literature divides processes into primary, auxiliary and managerial (Grajewski, 2012, p. 34). The first are related to the main activities of the organization and relate directly to the financial results, the second are infrastructure facilities for basic processes and constitute a source of costs. In turn, management processes are necessary for the proper functioning of the whole organization.

The direct transition from a functional organization to a process oriented one is related to redesigning of the entire organization (Table 1). Process identification and design, creating a system for measuring process efficiency and, last but not least, educating the crew about a new approach to the final result of the action becomes crucial. Piotr Grajewski correctly (Grajewski, 2016) points out a number of changes in the various organizational spheres of the company which must take place to make the company based on the functional system become a process-based company. Among the main changes the author mentioned: shifting the structure of the basic elements of the organization, changing the nature of the work performed from simple to multidimensional, replacing the individual responsibility for the performance of tasks to co-responsibility for results achieved, change in the organizational structure, change of results appraisal, change of employee status as well as change of corporate culture. 
Table 1.

Transforming a functional organization into a process oriented one

\begin{tabular}{|c|l|l|}
\hline $\begin{array}{c}\text { Structure } \\
\text { features }\end{array}$ & \multicolumn{1}{|c|}{ Functional organization } & \multicolumn{1}{c|}{ Process oriented organization } \\
\hline Specialization & $\begin{array}{l}\text { Separated functions as the basis for unit } \\
\text { grouping. Improving skills in order to unify } \\
\text { limited impact operations. }\end{array}$ & $\begin{array}{l}\text { Economic processes as the basis for the } \\
\text { creation of interdisciplinary teams. } \\
\text { Improving interdisciplinary skills. }\end{array}$ \\
\hline Centralisation & $\begin{array}{l}\text { Formal, multi-level power. } \\
\text { Domination of power relations over co- } \\
\text { operation. Real responsibility difficult to } \\
\text { determine. }\end{array}$ & $\begin{array}{l}\text { Dominance of horizontal relationships over } \\
\text { hierarchical. } \\
\text { The owner of the process replaces the } \\
\text { coordinating function of the current manager. } \\
\text { Responsibility for the actual results of the } \\
\text { work, the degree of satisfaction of the } \\
\text { customer. }\end{array}$ \\
\hline Formalization & $\begin{array}{l}\text { Decision-making powers associated with a } \\
\text { formal hierarchical position. The whole } \\
\text { image is obtained at the top of the pyramid } \\
\text { of power. Activity of workers directed to } \\
\text { activities in accordance with } \\
\text { predetermining procedures. }\end{array}$ & $\begin{array}{l}\text { Delegating permissions to process managers. } \\
\text { Independent contractors in creating process } \\
\text { Relatively long petrification of the } \\
\text { procedural rules related to the high cost of } \\
\text { Employee activity aimed at seeking effective } \\
\text { implementation procedures. }\end{array}$ \\
\hline
\end{tabular}

Note: (Grajewski, 2016, p. 169).

\section{Functional or process approach. What to choose? - discussion}

All decisions taken in contemporary business entities should take account of customers' needs and expectations. Customers' needs are treated as a prerequisite integrating all the functions and processes in the organization. Both the functional and procedural approach have specific advantages and disadvantages with supporters in various organizations, also in multientity ones. In business practice the ' purely' functional solutions are more often dominant than the process or mixed ones. For the latter, there are different configurations of domination of functions over processes or processes over functions. Each of these solutions can bring the desired results to the organization at a given stage of its organizational life. Successively, redesigning organizations from function orientation to process orientation carries a number of cultural, economic and managerial effects. Therefore, giving only one answer to the question stated in the title of this chapter would be a theoretical abuse and would not have a great value from a practical point of view. The complexity of the organization, its surroundings, and the challenges it is facing are forcing the managers to search for optimal organization forms in the living conditions of the organization. Hence, it is worthwhile to analyse the pros and cons of individual approaches in managing the organization to come closer to the answer to the matter in question. 
Organizations with functional orientation are able to better cope with the conditions of minor environmental changes. It is, in a sense, a stagnative organizational form. There are no developed mechanisms for rapid response and adaptation to environmental conditions. This is because of the concentration of tasks around the functions, care for the achievement of autonomous objectives assigned to specific organizational units, weak links with other functional spheres, long decision-making processes, reluctance to changes as well as extended bureaucracy. Functional management focuses on the planning and execution of tasks. The negative phenomenon that can occur in this type of organizational form is treating the objectives of the organizational unit as more important than the objectives of the whole organization. In particular, this may occur not only in an organizationally unconcentrated enterprise, but in a multi-entity organization where each of the internal members (e.g. subsidiaries) seeks to distinguish themselves from the group in the implementation of their own goals to acquire more advantageous resources. Furthermore there is a fear of excessive expansion of specific tasks within duplicated functions in these types of entities (e.g. procurement located in each subsidiary). Difficulties may arise in their coordination as a result. What is more, there is a tendency to centralize. Independent decision-making of individual organizational unit managers is largely controlled by the top-level management board. Subsidiary-level managers can be limited by top management to a greater or lesser extent. Thus, like any other organizational form, the functional organization also has specific advantages that can be considered as follows:

- professionalization of employees in the realization of a particular function, knowledge, skills, experience is concentrated around task/tasks,

- transparent division of tasks, powers, responsibilities,

- tendency to centralize decisions favours control and maintenance of power at the highest levels of the organization management,

- tendency to maintain the organization's integrity in case of multi-entity organizations, among others.

The application of an economic process approach in business practice may face a number of problems, including:

- redesigning the organization,

- awareness and orientation of the staff on the process,

- corporate culture,

- incentive scheme,

- building relationships within the organization.

In addition, in a multi-entity organization, processes are not carried out exclusively in one compact economic body but in a spread organization composed of many business entities. This undoubtedly makes it difficult to redesign the organization from function orientation to 
process orientation as well as hinders process designs, their implementation and management over such.

There is no doubt that the significant benefit of the implementation of the process approach is the "full" focus of the organization on customer satisfaction. All activities within the framework of the processes designed and subsequently implemented are used. Process oriented organizations adapt faster to situations and are prepared for changes in the environment. Processes are subject to measurement, analysis as well as improvement and the knowledge gained is used to reduce the in-house risks as well as risks in its surroundings. The flat structures dominate eliminating intermediate managerial positions. Participants, managers and direct contractors are involved in the process improvement or redesign. This, in turn, involves assigning more freedom of action to the above mentioned. It is especially important because comparing the functional organization to the process oriented one, in the latter one the increases of the intellectual potential of employees can be observed, the significance of workers' units rises, creativity among the staff is released as well as interorganizational and regardless of taken position expertise develops. Employees do not narrow their skills to a particular function, they go beyond the schemes of functional organization in the direction of interdisciplinarity and teamwork. As a result the entire staff is responsible for the final product and therefore for customer satisfaction which promotes the growth of organizational efficiency. The considerations presented here are confirmed in empirical studies. The research carried out by M. Kunesza (Kunesza, 2013, pp. 12-13) on a sample of more than 600 companies located in West Pomeranian and Lubuskie voivodeship in the area of selected aspects related to the problem of process management has shown that:

- procedural organizations are open to proposals for improvements in the organization suggested by employees (as a part of the continuous improvement philosophy) to a greater extent,

- there is a distinctly stronger focus on the client in procedural organizations, such organizations are investigating and taking into account their expectations and requirements.

To sum up the considerations in this part of the article, it should be noted that the process approach compared to functional one comes with greater dynamics in management, whole staff focus on final-product and openness to the employees ideas.

\section{Methodology of the studies and characteristics of surveyed entity}

The following question was posed in the study process: is a functional or procedural approach a dominant one in a subsidiary of a national German group? It was assumed that the answer to this question can be found by: 
- identification of the type of organizational structure of the company and the subsidiaries and the criteria by which the individual entities of the organization (organizational units, departments, sections) have been created determining the dominant positions of organizational units,

- identification of processes, process managers/leaders, dominant relationships (horizontal or hierarchical)

The following assumptions were made for the purpose of the research procedure:

- the main criterion for selecting the research entity was the availability of data,

- the studies were conducted in a subsidiary of a national German group,

- a case study procedure was used for research purposes and a method of analysing the content of the company's organizational documents and an individual interview with a list of open questions was used in the case study procedure,

- an individual interview was conducted with the managing director of the company (also acting as a procuration holder) and the aim was to obtain detailed information on the analysed issues,

- the study was conducted at the turn of 2018-2019.

The entity researched was a subsidiary of a national German group. The company was established in 1998. It specializes in the production of metal components and car seats. During twenty-one years of the company's functioning the headcount, technical infrastructure and the number of projects systematically increased. Two other production sites were established and they are directly subordinate to the subsidiary launched in 1998. The whole group consists of production facilities located in Poland, Germany and China. German entities operate on a JIT basis. They receive metal constructions of seat racks e.g. from the sites located in Poland, then they upholster them in Germany and supply them to car manufacturers. There is a high level of automation in operations in these plants. The company in China manufactures metal components and ready-made car seats for car mounts (sister company). The whole process starting with the production of metal parts of the seat, ending with upholstering them - takes place on site. The organizational structure of the group is shown in Figure 1.

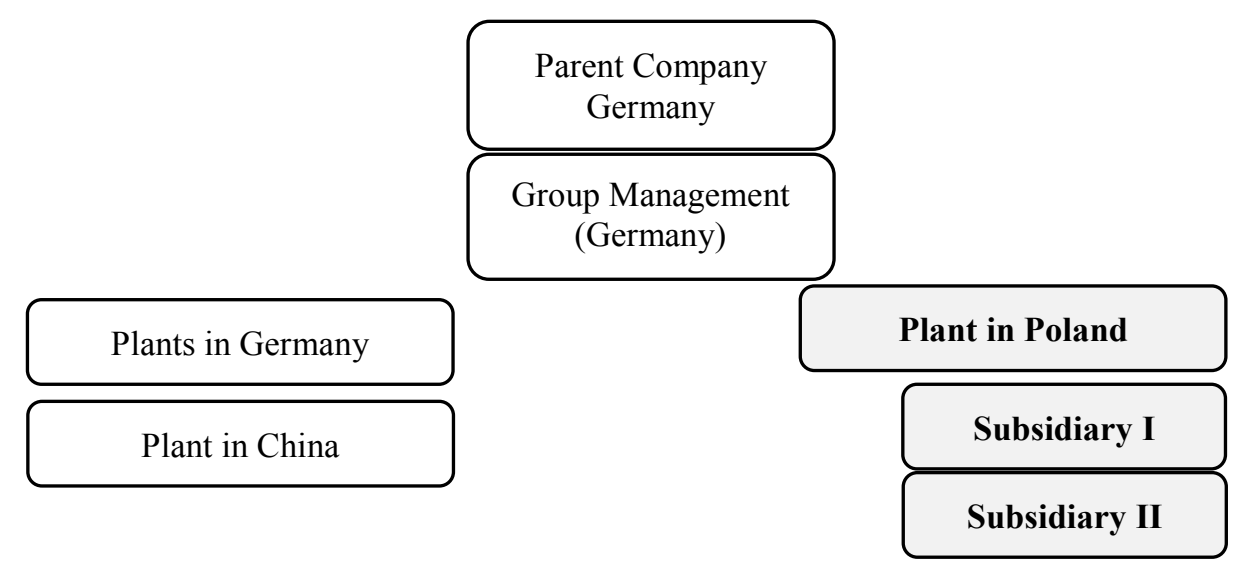

Figure 1. Organizational structure of the group with a distinguished research entity. Note: Own elaboration based on research results. 


\section{Research results}

The Polish group specializes in the production of metal components, car seat racks and finished car seats. The final products - car seats - are supplied to the car assembling facilities of the parent company. The company independently implements the entire manufacturing process of car seats in Poland with the support of the local subsidiaries.

The first research issue was to establish the type of organizational structure of the company and the subsidiaries, the criterion by which the individual entities of the organization (organizational units, departments, sections) have been created determining the dominant positions of organizational units.

The studies carried out show that:

- in all units of the group there are functional structures and the individual entities of the organization are created using the enterprise function criterion (Table 2).

Table 2.

Organizational sections and functions located in the company and subsidiaries

\begin{tabular}{|c|c|c|}
\hline Ltd. (Poland) & Subsidiary I (Poland) & Subsidiary II (Poland) \\
\hline \multicolumn{3}{|c|}{ Main ORGANIZATIONAL SECTIONS } \\
\hline \multirow{4}{*}{$\begin{array}{c}\text { Production, Quality Assurance, Logistics, } \\
\text { Maintenance, R+D, Product Management } \\
\text { (sale + marketing), Purchases, Personnel, } \\
\text { Controlling, Accountancy }\end{array}$} & Production & Production (Maintenance) \\
\hline & Quality Assurance & Quality Assurance \\
\hline & Operational logistics & Operational logistics \\
\hline & Maintenance & \\
\hline
\end{tabular}

Note: Own elaboration based on research results.

- organizational sections are main elements of the structure in the company as assumed and production is the most developed one among them in terms of structural elements, e.g. organizational units as well as the number of employees,

- the creation of new units for the implementation of new tasks is carried out on a functional specialization basis within the existing organizational units,

- the company has features that are typical for a company independent on the market, ranging from a marketing-sales function as product management, through the search for new technological solutions in existing products and the creation of new projects in the framework of research and development functions, ending with the delivery of the final product to the customer, which serves the function of sales,

- the decision-making autonomy of the directors of the subsidiaries is determined (limited, increased) by the director of the company, but there is a tendency to increase the decision-making autonomy of the directors, e.g. in terms of the disbursement of funds, hiring of indirect labour and direct labour staff,

- the directors of the various organizational divisions of the company are given more decision-making autonomy while increasing their accountability, 
- in terms of production function business units were created where managers have considerable autonomy and such autonomy corresponds not only to the manufacturing of specific products but also to logistics operations, maintenance and staffing policies; such a solution ultimately creates a direct relation between the staff and responsibility for the final product,

- manufacturing subsidiaries are provided with many functions they do not have to deal with by the company on a central level,

- the proximity of subsidiary II to the parent company restricts the expansion of its logistic sphere, many tasks such as in the field of dispatching logistics, finished products, single parts are centrally implemented by the company,

- the location of the maintenance function in an independent unit of subsidiary I is caused by the automation of many operations carried out on site as opposed to plant II in which the vast majority of activities are manual.

The second issue of the research was the recognition of processes carried out in the company and subsidiaries, the identification of process managers/leaders, the dominant relationships (horizontal, hierarchical). The analysis of the collected research material shows that:

- the company has developed a manufacturing process for the final product (Figure 2) taking into account the role of the individual entities throughout the supply chain and the main and supporting processes concentrating them around the individual functions (Table 3).

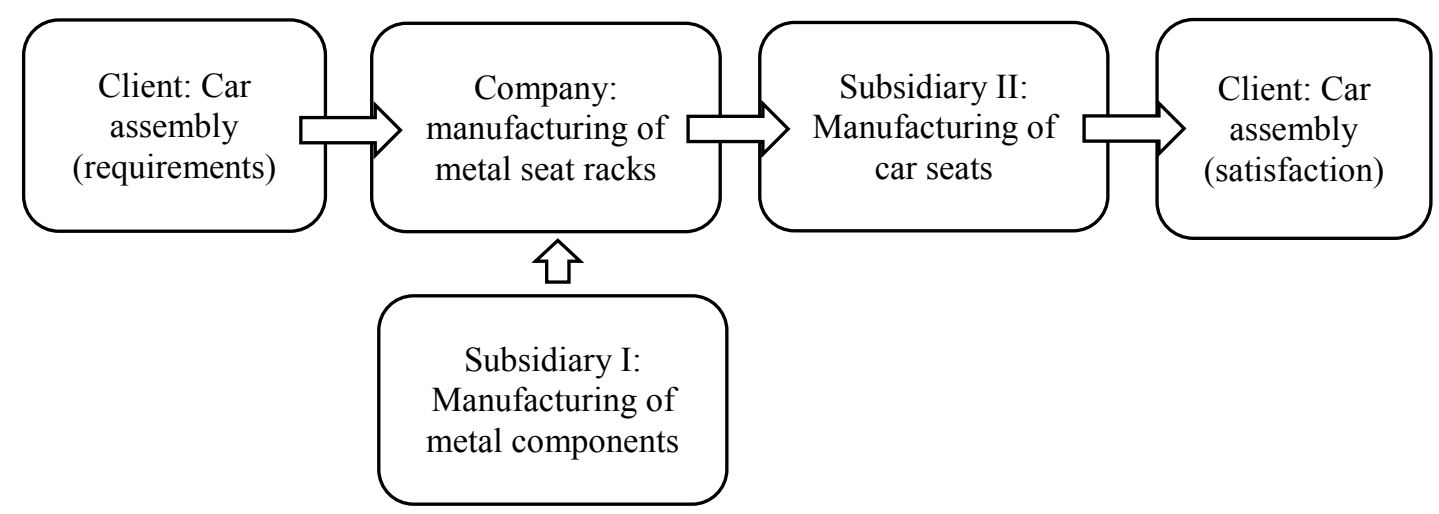

Figure 2. The process of producing the final product in the Polish group. Note: Own elaboration based on research results.

- within production process a number of operational processes have been separated,

- a process card has been developed within each function indicating the purpose of the process, scope, accountability and stages of the process, except that there are processes in which responsibility for the process goes beyond the function framework and different organizational units are held responsible for them e.g. in the field of personnel management in addition to the responsibility of the traditional human resources department, the company's management is responsible for identifying employment 
needs and qualification requirements for staff; on the other hand, there are processes such as purchase of material for which a particular organizational unit is responsible but the process involves not only the traditional purchasing department but also other units involved in the purchasing process,

- processes are subject to measurement, monitoring and improvement,

- no process managers, leaders or process management teams have been appointed,

- there are, however, task forces temporarily set-up to address current organizational problems,

- the organizational structure diagram does not show the processes carried out, only the functions implemented,

- hierarchical relationships dominate over horizontal ones.

Table 3.

Identification of processes carried out in the Polish group

\begin{tabular}{|c|c|c|c|c|}
\hline \multicolumn{5}{|c|}{ Main processes } \\
\hline \multicolumn{5}{|c|}{ Strategic management } \\
\hline \multicolumn{5}{|c|}{ Integrated quality, environment and OSH management System } \\
\hline \multicolumn{5}{|c|}{ Production } \\
\hline \multicolumn{2}{|c|}{$\begin{array}{l}\text { Company acting as headquarters and } \\
\text { production plant } \\
\text { Production processes: design, stamping, } \\
\text { painting, welding, assembly }\end{array}$} & \multicolumn{2}{|c|}{$\begin{array}{c}\text { Subsidiary II } \\
\text { Production processes: welding, } \\
\text { assembly }\end{array}$} & $\begin{array}{c}\text { Subsidiary III } \\
\text { Production processes: } \\
\text { assembly, foaming, } \\
\text { upholstery }\end{array}$ \\
\hline \multicolumn{5}{|c|}{ Supporting processes } \\
\hline Product Management & Res & ch and development & Plan & $\begin{array}{l}\mathrm{g} \text { and development of new } \\
\text { technologies }\end{array}$ \\
\hline Logistics & Huma & esources management & & Shopping \\
\hline Centralized maintenance & & dality Assurance & & Legal Department \\
\hline $\begin{array}{l}\text { Financial management and } \\
\text { controlling }\end{array}$ & & $\begin{array}{l}\text { duction systems } \\
\text { anological support }\end{array}$ & & Plant safety \\
\hline
\end{tabular}

Note: Own elaboration based on research results.

Summarizing the considerations in this part of the study the conclusion is that a Polish subsidiary of the German company applies a functional approach in management with elements of process orientation. Functions dominate the processes and are the main structure creating element. It seems reasonable that the next step towards a "full" process orientation should be the appointment of process managers/leaders and the reduction of the impact of functions in favour of processes.

\section{Closure}

To sum up the considerations related to the choice of a functional or procedural approach in management, several substantive conclusions can be formulated: 
- deciding on a change of approach in the management of a multi-entity organization should be well considered and preceded by a comprehensive analysis of the solutions guaranteeing optimal execution of the tasks resulting in customer satisfaction,

- while the functional approach exhausts, in a sense, the possibility of its further modification to achieve tangible benefits for the organization, the process approach, despite many problems it can generate and the scale of complexity in its implementation, gives greater benefits in terms of capacity to react to external imbalances,

- the traditional arrangement of functions based on the functional layout will continue to be of interest to the management of the parent unit and subsidiaries. The business practice provides many examples in this regard, including unsuccessful reorganizations in the "purely" process direction. One might even say that multi-entity organizations applying the parameters of the process organization in full are rather scarce,

- although the indirect solution between a purely procedural and functional organization generates a number of problems, this solution should be considered as a first step towards a process oriented organization, as is the case of the German company,

- the elaboration of the approach to management does not fully address the issues and concerns that are presented here. However, they point to many areas that need to be taken into account in further theoretical and empirical studies.

\section{References}

1. Cyfert, S., Krzakiewicz, K. (2006). The Concept of a process-oriented organization. In: J. Pyka (Eds.), Modernity of industry and services. Improvement of management as a source of competitive advantage. Katowice: TNOiK publishing House.

2. Grajewski, P. (2012). Process oriented organization Management. Warsaw: Polish Economic Publishing House.

3. Grajewski, P. (2016). Process Organization. Warsaw: Polish Economic Publishing House

4. Kunesza, M. (2013). Functional organization vs. process oriented organization. Test results. Enterprise Management, Iss. 4, 7-14.

5. Nowosielski, S. (2008). Process approach and modern concepts and methods of management. In: J. Lichtarski (Ed.), Directions and dilemmas of the development of science about the Enterprise. Scientific Work of the University of Economics, No. 34. Wrocław, 58-70. 